\title{
PENGARUH GAYA KEPEMIMPINAN, LINGKUNGAN KERJA, BUDAYA ORGANISASI, MOTIVASI KERJA DAN LOCUS OF CONTROL TERHADAP KINERJA INDIVIDU PADA UMKM DI KOTA PADANG
}

\author{
THE INFLUENCE OF LEADERSHIP STYLE, WORK ENVIRONMENT, \\ ORGANIZATIONAL CULTURE, WORK MOTIVATION AND LOCUS OF CONTROL \\ ON INDIVIDUAL PERFORMANCE IN UMKM IN PADANG CITY, WEST SUMATRA
}

Oleh:

Helmawati

Universitas Bung Hatta

Ethika

Universitas Bung Hatta

Rahmat Hidayat

Universitas Bung Hatta

\begin{abstract}
Abstrak
UMKM sangat berpengaruh pada perekonomian masyarakat. Berbagai upaya dilakukan pemerintah agar seluruh masyarakat memiliki penghasilan dan kalau memungkinkan memiliki usaha sendiri, seperti pelatihan, pembinaan dan pendampingan. Tetapi usaha tersebut tidak menjamin UMKM semakin meningkat, baik dari segi kuantitas maupun dari segi kualitas. Karena Jumlah penduduk menganggur di Sumatra Barat bertambah 12.800 orang dalam satu tahun belakangan, sejak 2016 hingga 2017. Padahal jika UMKM berkembang akan mempengaruhi kesejahteraan masyarakat karena akan mengurangi pengangguran dan meningkatkan indeks pembangunan manusia di sumatera barat. Bagus tidaknya kinerja UMKM sangat ditentukan oleh kinerja individu yang mengelola UMKM tersebut. Dan kinerja individu tersebut dapat dipengaruhi oleh berbagai faktor.

Oleh karena itu peneliti meneliti berbagai faktor yang diduga berpengaruh terhadap kinerja individu pada UMKM di kota Padang, seperti, gaya kepemimpinan, lingkungan kerja, budaya organisasi, motovasi kerja dan locus of control. Berdasarkan pengolahan data dengan program SPPS 16. Secara simultan keempat variabel itu tidak berpengaruh signifikan terhadap kinerja Pada UMKM Di Kota Padang tetapi secara parsial hanya variabel morivasi kerja yang berpengaruh terhadap kinerja individu pada derajat $\alpha 10 \%$. Dan besarnya variasi kemampuan keempat variabel itu dalam menjelaskan kinerja individu sangat kecil, yaitu $4,2 \%$.
\end{abstract}

Kata Kunci: UMKM, Gaya Kepemimpinan, Lingkungan kerja, Budaya Organisasi, Motivasi Kerja, Locus of Control, Kinerja individu.

\footnotetext{
Abstract

Micro, Small and Medium Enterprises (UMKM) play very influential role on the economy of society. Various efforts are made by the government so that all people have income and if possible have their own business, such as training, coaching and mentoring. However, the business does not guarantee the UMKM to increase, both in terms of quantity and quality because the number of unemployed population in West Sumatra increased 12,800 people in the past year, from 2016 to 2017. On the other hand, if UMKM develops, this will affect the welfare of the community because it will reduce unemployment and improve the human development index in western Sumatra. Excellent
} 
performance of SMEs is determined by the performance of individuals who manage MSMEs and individual performance will be influenced by various factors.

In this study, researchers examined various factors that allegedly affect the individual performance of UMKM in the city of Padang namely, leadership style, work environment, organizational strength, work motivation and locus of control. Based on the simultaneously processing with SPPS program 16, the four variables show no significant effect on the performance of UMKM in Padang City, but partially only work motivation variables affect the individual performance at $\alpha 10 \%$ while the variation of ability of the four variables in explaining individual performance is very small, which is $4,2 \%$.

Keywords: UMKM, Leadership Style, Work Environment, Organizational Culture, Work Motivation, Locus of Control, Individual Performance.

\section{PENDAHULUAN}

Latar Belakang

Saat ini, UMKM di Indonesia terus berkembang. Namun, pertumbuhannya belum diimbangi peningkatan kualitas. Hal ini membutuhkan perhatian serius dari semua pihak, terlebih dalam menghadapi era perdagangan bebas ASEAN (AFTA) atau Masyarakat Ekonomi ASEAN (MEA) 2015.

Tabel 1. Jumlah UMKM, Indeks Pembangunan Manusia dan Angka Pengangguran Sumatera Barat

\begin{tabular}{|l|c|c|c|}
\hline Tahun & $\begin{array}{c}\text { UMKM } \\
\text { kota } \\
\text { Padang }\end{array}$ & IPM & $\begin{array}{l}\text { Angka } \\
\text { Pengangguran } \\
\text { Sumbar }\end{array}$ \\
\hline 2011 & 35.123 & 78,68 & $6,45 \%$ \\
\hline 2012 & 35.331 & 79,00 & $6,50 \%$ \\
\hline 2013 & 70.980 & 79,23 & $6,89 \%$ \\
\hline 2014 & 74.062 & 79,83 & $6,50 \%$ \\
\hline 2015 & 76.236 & 70,18 & $6,89 \%$ \\
\hline 2016 & $*$ & 70,78 & $5,09 \%$ \\
\hline
\end{tabular}

Sumber : Badan Pusat Statistik

(*) Angka tidak ditemukan

Banyak upaya yang dilakukan pemerintah dalam rangka penguatan UMKM, Pemerintah Kota Padang melalui Dinas Koperasi dan UMKM Kota Padang melakukan pembinaan dan menyelenggarakan beberapa pelatihan, seperti: pelatihan pembuatan kemasan hasil produk, mutu desain data, mutu kualitas produk (LDII.or.id). melatih pembukuan dan membuat laporan keuangan agar dapat mengevaluasi

usahanya

(MinangkabauNws). Sehingga UMKM bisa sukses sesuai dengan kinerja yang diharapkan. Kesuksesan suatu UMKM sangat ditentukan oleh individu yang mengelola-nya. Oleh karena itu sangat diharapkan agar setiap pemilik dan pengelola UMKM memiliki kinerja yang bagus. Dan oleh sebab itu sangatlah penting mengetahui faktor-faktor yang diperkirakan dapat mempengaruhi kinerja individu pada UMKM tersebut.

Berdasarkan uraian di atas, landasan teori dan beberapa penelitian sebelumnya, peneliti melakukan penelitian terhadap variabel yang mungkin dapat mempengaruhi kinerja individu pada UMKM, dengan judul," Pengaruh Gaya Kepemimpinan, Lingkungan Kerja, Budaya Organisasi, Motivasi Kerja Dan Locus Of Control Terhadap Kinerja Individu Pada UMKM Kota Padang”. Permasalahan yang penulis rumuskan adalah sebagai berikut: Apakah gaya kepemimpinan, lingkungan kerja, budaya organisasi, motivasi kerja, dan locus of control berpengaruh terhadap kinerja individu pada UMKM di Kota Padang?. Dan penelitian ini bertujuan untuk membuktikan secara empiris: Apakah gaya kepemimpinan, lingkungan kerja, budaya organisasi, motivasi kerja, dan locus of control berpengaruh terhadap kinerja individu pada UMKM di Kota Padang?. Diharapkan dari penelitian ini dapat bermanfaat secara teoritis maupun praktis. 


\section{Kinerja Individu}

Menurut Engko (2006) Kinerja individual merupakan tingkat pencapaian atau hasil kerja seseorang dari sasaran yang harus dicapai atau tugas yang harus dilaksanakan dalam kurun waktu tertentu. Kinerja individual yang tinggi dapat meningkatkan kinerja organisasi secara keseluruhan. Kinerja seseorang dapat dikatakan baik, jika seseorang tersebut mempunyai keahlian yang tinggi, kesedian untuk bekerja, adanya imbalan/upah yang layak dan mempunyai harapan yang layak dimasa yang akan datang. Tinggi rendahnya kinerja seorang pegawai tentunya ditentukan oleh faktor-faktor yang mempengaruhinya baik secara langsung ataupun tidak langsung.

\section{Gaya Kepemimpinan}

Gaya kepemimpinan merupakan norma perilaku yang digunakan seseorang pada saat orang tersebut mencoba mempengaruhi perilaku orang lain seperti yang ia lihat. Dalam hal ini usaha menyelaraskan persepsi diantara orang yang akan mempengaruhi perilaku dengan orang yang perilakunya akan dipengaruhi menjadi amat penting kependudukannya (Thoha, 2009).

\section{Lingkungan Kerja}

Lingkungan kerja adalah sesuatu yang ada disekitar para pekerja dan yang mempengaruhi dirinya dalam menjalankan tugas-tugas yang dibebankan (Nitisemito, 1992). Selanjutnya menurut Sedarmayanti (2001) lingkungan kerja merupakan kseluruhan alat perkakas dan bahan yang dihadapi, lingkungan sekitarnya dimana seseorang bekerja, metode kerjanya, serta pengaturan kerjanya baik sebagai perseorangan maupun sebagai kelompok. Kondisi lingkungan kerja dikatakan baik atau sesuai apabila manusia dapat melaksanakan kegiatan secara optimal, sehat, aman, dan nyaman. Kesesuaian lingkungan kerja dapat dilihat akibatnya dalam jangka waktu yang lama lebih jauh lagi lingkungan-lingkungan kerja yang kurang baik dapat menuntut tenaga kerja dan waktu yang lebih banyak dan tidak mendukung diperolehnya rancangan sistem kerja yang efisien (Sedarmayanti, 2001).

Menurut Bambang (1991), lingkungan kerja merupakan salah satu faktor yang mempengaruhi kinerja seorang pegawai. Seorang pegawai yang bekerja di lingkungan kerja yang mendukung dia untuk bekerja secara optimal akan menghasilkan kinerja yang baik, sebaliknya jika seorang pegawai bekerja dalam lingkungan kerja yang tidak memadai dan tidak mendukung untuk bekerja secara optimal akan membuat pegawai yang bersangkutan menjadi malas, cepat lelah sehingga kinerja pegawai tersebut akan rendah.

Dari beberapa pendapat di atas dapat disimpulkan bahwa lingkungan kerja merupakan segala sesuatu yang ada disekitar pegawai pada saat bekerja, baik berbentuk fisik atau non fisik, langsung atau tidak langsung, yang dapat mempengaruhi dirinya dan pekerjaannya saat bekerja.

\section{Budaya Organisasi}

Wibowo (2007) Budaya organisasi adalah norma-norma dan kebiasaan yang di terima sebagai suatu kebenaran oleh semua orang dalam organisasi. Budaya organisasi menjadi acuan bersama diantara manusia dalam melakukan interaksi dalam organisasi. Budaya organisasi adalah bagaimana orang merasakan tetang pekerjaan baik dan apa yang membuat orang bekerja bersama dalam harmoni. Budaya organisasi merupakan perekat bagi semua hal didalam organisasi.

\section{Motivasi Kerja}

Terry, dkk (2010) Motivasi menyangkut perilaku manusia dan merupakan sebuah unsur yang vital dalam majemen. Ia dapat di definisiskan sebagai membuat seseorang menyelesaikan pekerjaan dengan semangat, karena orang itu ingin melakukannya. Motivasi berbeda diantara orang-orang, ia tergantung dari 
banyak faktor-faktor seperti kewibawaan, ambisi, pendidikan, dan umur. Guay dalam Priansa (2014) menyatakan bahwa motivasi mengacu pada alasan yang mendasari perilaku. Ada tiga elemen kunci dalam motivasi yaitu upaya, tujuan organisasi dan kebutuhan. Upaya merupakan ukuran intensitas. Bila seseorang termotivasi maka ia akan berupaya sekuat tenaga untuk mencapai tujuan, namun belum tentu upaya yang tinggi akan menghasilkan kinerja yang tinggi.

\section{Locus of Control}

Robbins dan Judge (2007) mendefinisikan lokus kendali sebagai tingkat dimana individu yakin bahwa mereka adalah penentu nasib mereka sendiri. Konsep tentang Locus of control (pusat kendali) pertama kali dikemukakan oleh Rotter (1966), seorang ahli teori pembelajaran sosial. Locus of control merupakan salah satu variabel kepribadian (personility), yang didefinisikan sebagai keyakinan individu terhadap mampu tidaknya mengontrol nasib (destiny) sendiri (Kreitner dan Kinicki, 2005).

Konsep tentang locus of control yang digunakan Rotter (1966) memiliki empat konsep dasar, yaitu: potensi perilaku, harapan, nilai unsur penguat, dan suasana psikologis.

\section{Pengaruh Gaya Kepemimpinan Terhadap Kinerja Individu}

Hasil penelitian Mitzberg (Covey, 2005) menyatakan bahwa bawahan akan termotivasi untuk bekerja lebih baik apa bila ada upaya-upaya pemberdayaan. Hasil penelitian dari Widodo (2010), Wahyuni (2015), dan Riyadi (2011) manunjukan bahwa Gaya Kepemimpinan mampu digunakan dalam memprediksi kinerja karyawan dan berpengaruh positif.

Hipotesis 1: Gaya kepemimpinan berpengaruh terhadap kinerja individu pada UMKM di Kota Padang.

\section{Pengaruh Lingkungan KerjaTerhadap} Kinerja Individu

Hasil penelitian Ethika (2016), Widodo (2010), menemukan adanya pengaruh yang signifikan antara lingkungan kerja terhadap kinerja kerja karyawan. Namun berbeda dengan penelitian Dhermawan (2012), lingkungan kerja tidak berpengaruh signifikann terhadap tidak berpengaruh signifikan terhadap kinerja.

Hipotesis 2: Lingkungan kerja berpengaruh terhadap kinerja individu individu pada UMKM di Kota Padang.

\section{Pengaruh Budaya Organisasi terhadap Kinerja Individu}

Penelitian Kotter dan Hekset (1992) menunjukkan bahwa budaya membantu (pada perusahaan lain menurunkan) kinerja ekonomi perusahaan dalam jangka panjang. Kinerja perusahaan dilihat dari laporan keuangan yang didasarkan pada standar akuntansi keuangan. Hasil penelitian Mediaty (2010), Wahyuni (2015), Widodo (2010), dan Edy (2008) menujukkan bahwa budaya organisasi mempunyai pengaruh positif dan signifikan terhadap kinerja kerja karyawan. Sedangkan penelitian Ethika (2016) budaya organisasi tidak berpengaruh terhadap kinerja individu.

Hipotesis 3: Budaya organisasi berpengaruh terhadap kinerja individu pada UMKM di Kota Padang.

\section{Pengaruh Motivasi Kerja Terhadap Kinerja Individu}

Hasil penelitian Hartati (2005), Hailesilasie (2009), Shadare dan Hammed (2011), Mahennoko (2011), Riyadi (2011), Ethika (2016), Supriyani dan Mahmud (2012) dan Andico et al (2013) menyimpulkan bahwa motivasi berpengaruh positif terhadap kinerja karyawan dalam bekerja. Namun berbeda dengan penelitian yang dilakukan Dhino (2015) Motivasi kerja tidak berpengaruh signifikan terhadap 
kinerja karyawan Dinas Sosial Tenaga Kerja Sumatera Barat.

Hipotesis 4: Motivasi kerja berpengaruh terhadap kinerja individu pada UMKM di Kota Padang.

\section{Pengaruh Locus of Control Terhadap Kinerja Individu}

Hasil penelitian Ayudiati (2011) dan Kurniawati (2007), bahwa locus of control berpengaruh positif pada kinerja individu. Tetapi penelitian Fratama (2014), menunjukkan bahwa pengaruh antara locus of control dengan kinerja karyawan tidak signifikan.

Hipotesis 5: Locus of control berpengaruh terhadap kinerja individu pada UMKM di Kota Padang.

\section{METODE PENELITIAN}

Populasi dan Sampel

Populasi dalam penelitian ini adalah pelaku usaha Mikro, Kecil dan Menengah yang ada di kota Padang. Sedangkan sampel adalah sebahagian dari populasi yang dipilih dengan menggunakan metode Convenience sampling,

\section{Sumber Data dan Teknik Pengumpulan Data}

Data yang digunakan adalah data primer. Metode pengumpulan data dalam penelitian ini menggunakan instrument berupa kuesioner dengan memberikan daftar pertanyaan tertulis kepada resoponden, yaitu karyawan UMKM di Kota Padang.

\section{Variabel Penelitian dan Pengukuran Variabel Penelitian}

Dalam penelitian ini, peneliti menggunakan empat variabel independen, yaitu lingkungan kerja, budaya organisasi, motivasi kerja dan locus of Control dan satu variabel dependen yaitu kinerja individu. Kuesioer untuk mengetahui pendapat responden. Kuesioner yang disebarkan memakai 5 skala likert.

\section{Metode Analisis Data dan Hipotesa}

Analisis data penelitian ini dengan menggunakan regresi linier berganda, yaitu untuk mengetahui bagaimana variabel dependent dapat diprediksi melalui variabel - variabel independent secara individual ataupun secara bersama-sama. Setelah melakukan analisis: Statistik deskriptif, Uji validitas, Uji Reliabilitas dan uji asumsi klasik. Untuk menganalisis data digunakan analisis Statistical Package for Sosial Science (SPSS 16.0 for windows) dengan persamaan regresi berganda yang digunakan sebagai berikut:

$$
\mathrm{Y}=\alpha+\beta 1 \mathrm{X} 1+\beta 2 \mathrm{X} 2+\beta 3 \mathrm{X3}+
$$

$\beta 3 X 4+\beta 3 X 5+\varepsilon$

Dimana: $\quad Y$

Kinerja Individu

$$
\alpha
$$

Konstanta

$$
\beta 1, \beta 2, \beta 3, \beta 4, \beta 5=
$$

Koefisien Regresi

$$
\mathrm{X} 1=\text { Gaya }
$$

Kepemimpinan

X2
Lingkungan Kerja
X3

Budaya Organisasi

$\begin{array}{cc}\text { X4 } & = \\ \text { Xotivasi } & = \\ \text { Xocus of Control } & =\end{array}$

Locus of Control

$\varepsilon$

\section{Error Term}

Pengukuran dilakukan dengan menilai hasil uji koefisien determinan $\left(\mathrm{R}^{2}\right)$, yang bertujuan untuk mengukur seberapa jauh kemampuan model dapat menjelaskan variasi variabel dependen (Ghozali, 2013). Kemudian Uji F. yaitu untuk menunjukkan apakah semua variabel independen atau bebas yang dimasukkan dalam model mempunyai pengaruh secara bersama-sama terhadap variabel dependen/terikat. Dan uji $\mathrm{t}$, yaitu untuk melihat seberapa jauh pengaruh satu variabel penjelas/independen secara individual dalam menerangkan variasi variabel dependen. 


\section{HASIL PEMBAHASAN}

Hasil pengolahan data dan analisa yang dilakukan setelah peneliti menerima kuesioner yang telah disebarkan, adalah sebagai berikut:

\section{Statistik Responden}

Dari 100 lembar kuesioner yang disebarkan, yang bisa diolah sebanyak 90 . Dengan demikian tingkat responden penelitian adalah 90\%. Dan Profil dari responden adalah sebagai berikut:

Jenis Kelamin : Laki-Laki $(36,7 \%)$, Perempuan $(63,3 \%)$.

Usia : 17- $20(31 \%), \quad 21-$ 25 (38,9\%), 26-30 (20\%), 31- ke atas $(10,1 \%)$.

Pendidikan terakhir : $\quad$ SMU (80\%). Diploma (12\%), SI (8\%).

Dengan demikian diketahui bahwa mayoritas yang menjadi responden adalah perempuan sebanyak 57 orang $(63,3 \%)$. Paling banyak berusia kisaran 21 s/d 25 $(38,9 \%)$, dan pendidikan terakhir responden mayoritasnya adalah SMU sebanyak 72 responden $(80 \%)$.

Berikut adalah tabel statistik deskriptif data dari jawaban responden:

Tabel 2. Statistik Dekriptif

\begin{tabular}{|c|c|c|c|c|c|}
\hline \multirow{2}{*}{$\begin{array}{c}\text { Variabe } \\
1\end{array}$} & \multirow{2}{*}{$\mathbf{N}$} & \multicolumn{4}{|c|}{ Kisaran } \\
\hline & & $\begin{array}{c}\text { Teoriti } \\
\text { s }\end{array}$ & $\underset{\text { l }}{\text { Aktua }}$ & $\underset{\mathbf{n}}{\mathrm{Mea}}$ & Ket \\
\hline $\begin{array}{l}\text { Gaya } \\
\text { Kepe- } \\
\text { mimpi- } \\
\text { nan }\end{array}$ & $\begin{array}{l}9 \\
0\end{array}$ & $6-30$ & $\begin{array}{l}19- \\
29\end{array}$ & 24,21 & Bagus \\
\hline $\begin{array}{l}\text { Lingku- } \\
\text { ngan } \\
\text { Kerja }\end{array}$ & $\begin{array}{l}9 \\
0\end{array}$ & $6-30$ & $\begin{array}{l}15- \\
30\end{array}$ & 22,66 & $\begin{array}{l}\text { Cuku } \\
\mathrm{p} \\
\text { Bagus }\end{array}$ \\
\hline $\begin{array}{l}\text { Budaya } \\
\text { Organi- } \\
\text { sasi }\end{array}$ & $\begin{array}{l}9 \\
0\end{array}$ & $8-30$ & $\begin{array}{l}16- \\
40\end{array}$ & 29,93 & $\begin{array}{l}\text { Cuku } \\
\mathrm{p} \\
\text { Bagus }\end{array}$ \\
\hline $\begin{array}{l}\text { Motivasi } \\
\text { Kerja }\end{array}$ & $\begin{array}{l}9 \\
0\end{array}$ & $21-105$ & $\begin{array}{c}55- \\
105\end{array}$ & 76,59 & $\begin{array}{l}\text { Cuku } \\
\mathrm{p} \\
\text { Bagus }\end{array}$ \\
\hline $\begin{array}{l}\text { Locus of } \\
\text { Control }\end{array}$ & $\begin{array}{l}9 \\
0\end{array}$ & $5-25$ & $21^{5-}$ & 11,64 & $\begin{array}{l}\text { Tidak } \\
\text { Bagus }\end{array}$ \\
\hline $\begin{array}{l}\text { Kinerja } \\
\text { Individu }\end{array}$ & $\begin{array}{l}9 \\
0 \\
\end{array}$ & $4-20$ & $\begin{array}{l}11- \\
20\end{array}$ & 16,43 & Bagus \\
\hline $\begin{array}{l}\text { Valid N } \\
\text { (listwise }\end{array}$ & $\begin{array}{l}9 \\
0 \\
\end{array}$ & & & & \\
\hline
\end{tabular}

Sumber: Hasil Olahan SPSS

Berdasarkan tabel di atas, dari 90 responden tersebut, maka dapat dikatakan gaya kepemimpinan, kinerja individu dapat dinilai bagus, lingkungan kerja, budaya organisasi, motivasi karyawan cukup bagus tetapi locus of control dinilai kurang bagus.

\section{Hasil Uji Kualitas Data}

Berdasarkan Uji validitas dan uji reliabilitas yang dilakukan adalah sebagai berikut:

Tabel 3. Hasil Uji Validitas dan Reliabilitas

\begin{tabular}{|l|c|c|c|c|}
\hline Variabel & KMO & $\begin{array}{c}\text { Faktor } \\
\text { Loading }\end{array}$ & $\begin{array}{c}\text { Cron- } \\
\text { bach's } \\
\text { Alpha }\end{array}$ & $\begin{array}{c}\text { Kete- } \\
\text { rangan }\end{array}$ \\
\hline $\begin{array}{l}\text { Gaya } \\
\text { Kepemim- } \\
\text { pinan }\end{array}$ & 0,539 & $\begin{array}{c}0,419- \\
0,662\end{array}$ & 0,620 & $\begin{array}{c}\text { Valid, } \\
\text { Reabel }\end{array}$ \\
\hline $\begin{array}{l}\text { Lingkungan } \\
\text { kerja }\end{array}$ & 0,616 & $\begin{array}{c}0,551- \\
0,728\end{array}$ & 0,680 & $\begin{array}{c}\text { Valid, } \\
\text { Reabel }\end{array}$ \\
\hline $\begin{array}{l}\text { Budaya } \\
\text { Organisasi }\end{array}$ & 0,767 & $\begin{array}{c}0,492-- \\
0,823\end{array}$ & 0,789 & $\begin{array}{c}\text { Valid, } \\
\text { Reabel }\end{array}$ \\
\hline $\begin{array}{l}\text { Motivasi } \\
\text { Kerja }\end{array}$ & 0,755 & $\begin{array}{c}0,418- \\
0,730\end{array}$ & 0,881 & $\begin{array}{c}\text { Valid, } \\
\text { Reabel }\end{array}$ \\
\hline $\begin{array}{l}\text { Locus of } \\
\text { Control }\end{array}$ & 0,846 & $\begin{array}{c}0,791- \\
0,906\end{array}$ & 0,910 & $\begin{array}{c}\text { Valid, } \\
\text { Reabel }\end{array}$ \\
\hline $\begin{array}{l}\text { Kinerja } \\
\text { Individu }\end{array}$ & 0,679 & $\begin{array}{c}0,679- \\
0,788\end{array}$ & 0,713 & $\begin{array}{c}\text { Valid, } \\
\text { Reabel }\end{array}$ \\
\hline
\end{tabular}

Sumber: Hasil Olahan SPSS

Berdasarkan table 3 memperlihatkan semua variabel penelitian valid dan reabel karena nilai KMO lebih besar dari 0,50. Faktor loading lebih besar dari 0,4. Dan nilai Cronbach's Alpha $>0,60$.

\section{Hasil Uji Asumsi Klasik}

Berdasarkan hasil uji yang dilakukan ditampilkan pada tabel di bawah: 
Tabel 4. Hasil Uji Normalitas dan Multikolonieritas Data

\begin{tabular}{|c|c|c|c|c|c|}
\hline \multirow{3}{*}{ Variabel } & \multicolumn{2}{|c|}{ Normalitas } & \multicolumn{3}{|c|}{$\begin{array}{c}\text { Multikolonie- } \\
\text { ritas }\end{array}$} \\
\hline & \multirow{2}{*}{$\begin{array}{l}\text { Asy } \\
\text { mp } \\
\text { Sig }\end{array}$} & \multirow{2}{*}{ Ket } & \multicolumn{2}{|c|}{$\begin{array}{c}\text { Colli- } \\
\text { nearity } \\
\text { Statistics }\end{array}$} & \multirow{2}{*}{ Ket } \\
\hline & & & $\begin{array}{l}\text { To- } \\
\text { lera } \\
\text { nce } \\
\end{array}$ & $\begin{array}{l}\text { V } \\
\text { IF }\end{array}$ & \\
\hline $\begin{array}{l}\text { Gaya } \\
\text { Kepe- } \\
\text { mimpin- } \\
\text { an }\end{array}$ & $\begin{array}{c}0,36 \\
9\end{array}$ & $\begin{array}{l}\text { Nor- } \\
\text { mal }\end{array}$ & $\begin{array}{c}0,90 \\
2\end{array}$ & $\begin{array}{c}1, \\
10 \\
9\end{array}$ & \multirow{5}{*}{$\begin{array}{c}\text { Tidak } \\
\text { Terja- } \\
\text { di } \\
\text { Mul- } \\
\text { tiko- } \\
\text { linier- } \\
\text { itas }\end{array}$} \\
\hline $\begin{array}{l}\text { Ling- } \\
\text { kungan } \\
\text { Kerja }\end{array}$ & $\begin{array}{c}0,03 \\
3\end{array}$ & $\begin{array}{c}\mathrm{Ku}- \\
\text { rang } \\
\text { Nor- } \\
\text { mal }\end{array}$ & $\begin{array}{c}0,73 \\
2\end{array}$ & $\begin{array}{c}1, \\
36 \\
7\end{array}$ & \\
\hline $\begin{array}{l}\text { Budaya } \\
\text { Organi- } \\
\text { sasi }\end{array}$ & $\begin{array}{c}0,05 \\
4\end{array}$ & $\begin{array}{l}\text { Nor- } \\
\text { mal }\end{array}$ & $\begin{array}{c}0,71 \\
4\end{array}$ & $\begin{array}{c}1, \\
40 \\
0\end{array}$ & \\
\hline $\begin{array}{l}\text { Motivasi } \\
\text { Kerja }\end{array}$ & $\begin{array}{c}0,34 \\
7\end{array}$ & $\begin{array}{c}\text { Nor- } \\
\text { mal }\end{array}$ & $\begin{array}{c}0,84 \\
4\end{array}$ & $\begin{array}{c}1, \\
18 \\
6\end{array}$ & \\
\hline $\begin{array}{l}\text { Locus of } \\
\text { Control }\end{array}$ & $\begin{array}{c}0,29 \\
4\end{array}$ & $\begin{array}{c}\text { Nor- } \\
\text { mal }\end{array}$ & $\begin{array}{c}0,92 \\
5\end{array}$ & $\begin{array}{c}1, \\
08 \\
1\end{array}$ & \\
\hline $\begin{array}{l}\text { Kinerja } \\
\text { individu }\end{array}$ & $\begin{array}{c}0,16 \\
6 \\
\end{array}$ & $\begin{array}{l}\text { Nor- } \\
\text { mal }\end{array}$ & & & \\
\hline
\end{tabular}

Sumber : Hasil Olahan SPSS

Dari Tabel 4 dapat dikatakan hampir semua variabel yang digunakan berdistribusi normal dan bebas dari gejala multikolonieritas, karena memiliki nilai Asymp.Sig lebih besar dari 0,05, kecuali variabel locus of control. Dan semua nilai tolerance di atas 0,1 dan nilai VIF di bawah angka 10.

\section{Hasil Pengujian Hipotesa}

Berdasarkan hasil analisa data untuk menjawab hipotesa yang diajukan adalah sebagai berikut:
Tabel 5. Hasil Regresi Linier Berganda

\begin{tabular}{|c|c|c|c|c|c|}
\hline \multirow{2}{*}{$\begin{array}{c}\text { Kete- } \\
\text { rangan }\end{array}$} & \multicolumn{2}{|c|}{\begin{tabular}{|c|} 
Unstandar- \\
dized \\
Coeffici- \\
ents
\end{tabular}} & \multirow[t]{2}{*}{$\mathbf{t}$} & \multirow[t]{2}{*}{ Sig } & \multirow{2}{*}{$\begin{array}{l}\text { Ke- } \\
\text { tera- } \\
\text { ngan }\end{array}$} \\
\hline & B & $\begin{array}{l}\text { Std. } \\
\text { Er- } \\
\text { ror }\end{array}$ & & & \\
\hline $\begin{array}{l}\text { (Cons- } \\
\operatorname{tant})\end{array}$ & $\begin{array}{l}2,94 \\
8\end{array}$ & $\begin{array}{l}0,35 \\
7\end{array}$ & $\begin{array}{l}8,2 \\
62\end{array}$ & $\begin{array}{l}0,0 \\
00\end{array}$ & \\
\hline $\begin{array}{l}\text { Gaya } \\
\text { Kepe- } \\
\text { mimpin- } \\
\text { an }\end{array}$ & \begin{tabular}{|l}
0,00 \\
5
\end{tabular} & $\begin{array}{l}0,00 \\
8\end{array}$ & $\begin{array}{l}0,6 \\
13\end{array}$ & $\begin{array}{l}0,5 \\
42\end{array}$ & $\begin{array}{l}\text { H1 } \\
\text { dito- } \\
\text { lak }\end{array}$ \\
\hline $\begin{array}{l}\text { Ling- } \\
\text { kungan } \\
\text { kerja }\end{array}$ & $\begin{array}{l}- \\
0,00 \\
7\end{array}$ & $\begin{array}{l}0,00 \\
8\end{array}$ & $\begin{array}{l}- \\
0,8 \\
81\end{array}$ & $\begin{array}{l}0,3 \\
81\end{array}$ & $\begin{array}{l}\text { H1 } \\
\text { dito- } \\
\text { lak }\end{array}$ \\
\hline $\begin{array}{l}\text { Budaya } \\
\text { Organi- } \\
\text { sasi }\end{array}$ & $\begin{array}{l}0,01 \\
7\end{array}$ & $\begin{array}{l}0,05 \\
8\end{array}$ & $\begin{array}{l}0,2 \\
96\end{array}$ & $\begin{array}{l}0,7 \\
68\end{array}$ & $\begin{array}{l}\text { H1 } \\
\text { dito- } \\
\text { lak }\end{array}$ \\
\hline $\begin{array}{l}\text { Motivasi } \\
\text { Kerja }\end{array}$ & $\begin{array}{l}0,06 \\
8\end{array}$ & $\begin{array}{l}0,03 \\
4\end{array}$ & $\begin{array}{l}1,9 \\
96\end{array}$ & $\begin{array}{l}0,0 \\
49\end{array}$ & $\begin{array}{l}\text { H1 di- } \\
\text { teri- } \\
\text { ma }\end{array}$ \\
\hline $\begin{array}{l}\text { Locus of } \\
\text { Control }\end{array}$ & $\begin{array}{l}5.67 \\
9 \mathrm{E}-5\end{array}$ & $\begin{array}{l}0,00 \\
4\end{array}$ & $\begin{array}{l}0,0 \\
14\end{array}$ & $\begin{array}{l}0,9 \\
89\end{array}$ & $\begin{array}{l}\text { H1 } \\
\text { dito- } \\
\text { lak }\end{array}$ \\
\hline & $\begin{array}{l}=0 \\
\text { itung }\end{array}$ & $5 \mathrm{R}$ & $\overline{\text { aus }}$ & $\begin{array}{l}= \\
=0\end{array}$ & $\begin{array}{ll}42 & F \\
1 & \alpha\end{array}$ \\
\hline
\end{tabular}

Sumber :Hasil Olahan SPSS

$\mathrm{Y}=2,948+, 005 \mathrm{X}^{1}-0,007 \mathrm{X}^{2}+0,017 \mathrm{X}^{3}+$ $0,068 X^{4}+0,00005679 X^{3}+e$

Nilai R Square bernilai 0,042 atau $4,2 \%$ berarti kemampuan variasi variabel Independen menjelaskan variabel dependen $4,2 \%$ (sangat kecil) dan 95,8\% dijelaskan oleh variabel yang tidak diteliti dalam peneliti ini. Berdasarkan hasil uji $F$ menunjukkan semua variabel independen dalam model secara simultan tidak mempengaruhi variabel dependen karena nilai probabilitas signifikan $\mathrm{F}$ hitung 0,611 lebih besar dari alpha 0,05. dengan tingkat toleransi kesalahan sebesar 0,05 , 


\section{Hasil Signifikan Parameter Individual (Uji t)}

Tabel 5 menunjukkan hasil pengujian hipotesis 1 , yaitu variabel gaya kepemimpinan memperoleh nilai $\mathrm{t}$ hitung 6,13 dengan tingkat signifikan 0,000. Berarti $\mathrm{H}_{1}$ ditolak karena tingkat signifikansi lebih besar dari alpha 0,05. Ini menunjukkan bahwa gaya kepemimpinan tidak berpengaruh secara signifikan terhadap kinerja individu di UMKM kota Padang, meskipun pada penelitian ini lingkungan kerja UMKM kota Padang dinilai bagus, dan kinerja individu juga bagus. Hasi penelitian ini tidak mendukung hasil penelitian Wahyuni (2015), Widodo (2010), dan Riyadi (2011). Yang menyimpulkan bahwa gaya kepemimpinan berpengaruh positif terhadap kinerja pegawai.

Hasil pengujian hipotesis 2, yaitu variabel lingkungan kerja memperoleh nilai t hitung 0,014 dengan tingkat signifikan 0,989. Berarti $\mathrm{H}_{2}$ ditolak karena tingkat signifikansi lebih besar dari alpha 0,05. Ini menunjukkan bahwa lingkungan kerja bukanlah variabel yang signifikan mempengaruhi kinerja individu di UMKM kota Padang. Hasil penelitian ini konsisten dengan hasil penelitian Dhermawan (2012), lingkungan kerja tidak berpengaruh signifikan terhadap kinerja pegawai. Dan tidak mendukung penelitian Widodo (2010).

Hasil uji hipotesis 3, karena variabel budaya organisasi memiliki nilai $\mathrm{t}$ hitung 0,296 dengan tingkat signifikan sebesar 0,768. Sehingga $\mathrm{H}_{3}$ ditolak. Disimpulkan bahwa budaya organisasi tidak berpengaruh signifikan terhadap kinerja individu UMKM karena tingkat signifikansi variabel motivasi kerja lebih besar dari 0,05. Meskipun Budaya organisasi pada UMKM kota Padang dinilai cukup bagus, namun pada penelitian ini budaya organisasi pada UMKM yang bersangkutan bukanlah faktor yang dapat mempengaruhi secara signifikan kinerja individu karyawan UMKM tersebut. Hasil penelitian ini mendukung hasil penelitian Ethika (2016) tetapi tidak konsisten dengan hasil penelitian Mediaty
(2010), Wahyuni (2015), Widodo (2010), dan Edy (2008) yang menujukkan bahwa budaya organisasi mempunyai pengaruh positif dan signifikan terhadap kinerja kerja karyawan.

Hasil uji hipotesis 4, dimana variabel motivasi kerja memiliki nilai t hitung 1,996 dengan koefesien negative $(0,068)$ dan tingkat signifikan sebesar 0,049. Hal ini berarti $\mathrm{H}_{4}$ diterima pada level $\alpha=5 \%$ sehingga dapat disimpulkan bahwa motivasi kerja berpengaruh signifikan terhadap kinerja individu dengan hubungan yang positive, karena tingkat signifikansi variabel motivasi kerja lebih kecil dari 0,05. Artinya naik turunnya kinerja individu ditentukan oleh motivasi yang ada pada masing masing individu yang bersangkutan. semakin tinggi motivasi kerja karyawan UMKM semakin tinggi kinerja individu anggota UMKM. Apabila karyawan termotivasi dalam bekerja maka mereka akan berusaha berbuat sekuat tenaga untuk mewujudkan dan menyelesaikan apa yang menjadi tugas dan pekerjaanya. Artinya bahwa motivasi kerja dalam penelitian ini merupakan faktor yang mempengaruhi kinerja individu UMKM kota Padang.

Hasil penelitian ini sama dengan dengan hasil penelitian Hartati (2005), Hailesilasie (2009), Shadare dan Hammed (2011), Mahennoko (2011), dan Riyadi (2011). Yang menyimpulkan motivasi kerja berpengaruh signifikan dengan hubungan yang positif terhadap kinerja karyawan. Dan sangat berbeda dengan hasil penelitian yang dilakukan Dhino (2015) Motivasi kerja tidak berpengaruh signifikan terhadap kinerja karyawan Dinas Sosial Tenaga Kerja Sumatera Barat.

Dan hasil pengujian hipotesis 5 tentang variabel locus of control memiliki nilai $\mathrm{t}$ hitung 0,014 dengan tingkat signifikan sebesar 0,989. Sehingga $\mathrm{H}_{5}$ ditolak. Dapat disimpulkan bahwa locus of control tidak berpengaruh signifikan terhadap kinerja individu UMKM karena tingkat signifikansi variabel motivasi kerja lebih besar dari 0,05. Sehingga Locus of 
control bukanlah faktor yang dapat mempengaruhi kinerja individu karyawan UMKM tersebut secara signifikan. Hasil penelitian ini konsisten dengan penelitian Fratama (2014). Tetapi tidak mendukung hasil penelitian Ayudiati (2011) dan Kurniawati (2007) bahwa locus of control mempunyai pengaruh signifikan terhadap kinerja kerja karyawan.

\section{SIMPULAN DAN SARAN Simpulan}

Penelitian ini bertujuan untuk mengetahui pengaruh lingkungan kerja, budaya organisasi, dan motivasi kerja terhadap kinerja individu karyawan UMKM kota Padang. Responden penelitian berjumlah 90 karyawan dari 100 yang dijadikan sampel. Berdasarkan pengujian data dengan menggunakan model regresi berganda untuk membuktikan lima hipotesa, maka dapat diambil kesimpulan, bahwa motivasi kerja berpengaruh signifikan terhadap kinerja individu karyawan UMKM Kota Padang, tetapi gaya kepemimpinan, lingkungan kerja, budaya organisasi, dan locus of control tidak berpengaruh yang signifikan terhadap kinerja individu karyawan UMKM kota Padang

\section{Keterbatasan dan Saran}

Penelitian ini memiliki beberapa keterbatasan, antara lain: nilai koefisien determinan nya sangat kecil hanya $(4,2 \%)$ dan sampel yang sedikit dibandingkan populasi yang ada, yang mungkin kurang mewakili populasi UMKM di Kota Padang. Sehingga untuk peneliti selanjutnya perlu menggunakan jumlah sampel yang lebih banyak, dan mencoba variabel lain yang mungkin mempengaruhi kinerja individu UMKM.

Bagi pemilik UMKM dan dan instansi yang terkait dapat dijadikan masukan bahwa banyak faktor yang akan mempengaruhi kinerja karyawan karena ternyata dalam penelitian ini gaya kepemimpinan, lingkungan kerja, budaya organisasi dan locus of control juga tidak selalu dapat mempengaruhi kinerja karyawan UMKM sehungga harus lebih cermat dalam mengamati kinerja karyawannya dan mencoba mencari faktor faktor yang mungkin bisa meningkatkan kinerja karyawan UMKM.

\section{DAFTAR PUSTAKA}

Andiko Hari, Ali Imran dan Muthia. 2013. Pengaruh Kompensasi, Penghargaan Aktualisasi Diri Terhadap Kepuasan Karyawan Perusahaan Perbankan di Jakarta. Jurnal Ekonomi dan Bisnis Volume 2 Nomor 2. Universitas Dipenegoro, Semarang.

Ayudiati, Soraya. 2011. Pengaruh Locus of Control Terhadap Kinerja denagn Etika Kerja Islam Sebagai Variabel Moderating pada Karyawan Bank Jateng Semarang.

Bambang, Kussriyanto. 1991. Peningkatan Produktivitas Karyawan. Jakarta: PT Gramedia

Covey R Sthepen, 2005. The $8^{\text {th }}$ Habit. Jakarta PT Gramedia Pustaka Utama.

Dhermawan, Anak Agung Ngurah Bagus dan Sudibya, I Gde Adnyana dan Utama, I Wayan Mudiartha. 2012. "Pengaruh Motivasi, Lingkungan Kerja, Kompensasi, dan Kompensasi terhadap Kepuasan Kerja dan Kinerja Pegawai di Lingkungan Kantor Dinas Pekerjaan Umum Provinsi Bali". Jurnal Manajemen, Strategi Bisnis, dan Kewirausahaan. Fakultas Ekonomi Universitas Udayana.

Dhino, Steffi Rahma. 2015. "Pengaruh Kepuasan Kerja, Kompensasi, Motivasi Kerja, dan Komitmen Organisasi terhadap Kinerja Karyawan Dinas Sosial Tenaga Kerja Sumatera Barat". Skripsi. Fakutas Ekonomi Universitas Bung Hatta.

Edy. 2008. Pengaruh Budaya Organisasional dan Lingkungan Kerja Terhadap Kinerja Perawat "Rumah Sakit Mata Dr. Yap" Yogyakarta dengan 
motivasi dan Kepuasasn Kerja Sebagai Variabel Pemediasi. Jurnal Ekonomi dan Bisnis. ISSN: 19783116.

Engko, Cecilia, 2006. Pengaruh Kepuasan Kerja Terhadap Kinerja Individual dengan Self Esteem dan Self efficacy variable intervening. Simposium Nasional Akuntansi 9. Padang.

Ethika, 2016 "Pengaruh Lingkungan Kerja, Budaya Organisasi dan Motivasi Terhadap Kinerja Individu pada UMKM Kota Padang. Prosiding Seminar Internasional Koperasi dan UMKM di Padang.

Fratama, Annissa. 2014. "Pengaruh Kepercayaan Diri, Locus Of Control, Motivasi terhadap Kinerja Karyawan". Skripsi. Fakutas Ekonomi Universitas Bung Hatta.

Ghozali, Imam. 2013. Aplikasi Analisis Multivariate dengan Program SPSS. Semarang: Balai Penerbit Universitas Diponegoro.

Ghozali, Imam. 2011. Aplikasi Analisis Multivariate dengan Program IBM SPSS 19 Badan Penerbit Universitas Diponegoro

Hailesilasi, G. 2009. "Determinants Of Public Employess' Performance: Evidence From Ethiophian Public Organization". International Journal of Productivity an Performance Management, Vol.58, No.3, hal. 238:253.

Hartati. 2005. "Pengaruh Kesesuaian Kompetensi dan Motivasi terhadap Kinerja Pegawai pada Sekretariat Daerah Kabupaten Malang”. JurnalEksekutif, Vol. 2, No.1, hal.63:80.

J.B. Rotter (1966) Generalized expectancies for internal versus external control of reinforcement, Psychological Monographs, 80, (1, Whole No. 609).

Kreitner Robert dan Angelo Kinicki. 2005 Organizational Behaviour. Mc
Graw-Hill New York Companies Inc.

Kurniawati, Nurul Imani. 2007. Analisis Pengaruh Locus of Control Terhadap Kinerja Karyawan dengan Kepuasan Kerja sebagai Variabel Moderating.

Mahennoko, Anandhika Angga. 2011. Pengaruh Motivasi Kerja dan Komitmen Organisasi Terhadap Kinerja Pegawai Bidang Keuangan Pada Pemerintah Daerah Kabupaten Demak. Semarang: Universitas Diponegoro.

Mediaty. 2010. Analisis Pengaruh Lingkungan strategi, Budaya, dan Perencanaan Strategi terhadap Kinerja Perusahaan Daerah. SNA XIII, Universitas Jendral Soedirman Purwokerto.

Nitisemito. Alex S. 1996. Manajemen Personalia: Manajemen Sumber Daya Manusia, Ed.3. Jakarta: Ghalia Indonesia.

Priansa, Donni Juni. 2014. Perencanaan dan Pengembangan Sumber Daya Manusia. Bandung: Alfabeta.

Riyadi, Slamet. 2011. "Pengaruh Kompensasi Finansial, Gaya Kepemimpinan, dan Motivasi Kerja terhadap Kinerja Karyawan pada Perusahaan Manufaktur di Jawa Timur". Jurnal Manajemen dan Kewirausahaan. Vol. 13. No. 1. Maret 2011. Hal. $40-45$. Universitas 17 Agustus 1945 Surabaya. Surabaya.

Robbbins dan Judge. 2007. Perilaku Organisasi, Jakarta: Salemba Empat

Sasmita Hana dan Ethika. 2016. Pengaruh "Pengaruh Budaya Organisasi, Motivasi Kerja dan Locus of Control terhadap Kinerja Individu pada Koperasi di Kota Padang". Prosiding Seminar Internasional Koperasi dan UMKM di Padang.

Sedarmayanti. (2001). Sumber Daya Manusia dan Produktivitas Kerja. Jakarta Mandar Maju. 
Shadare, O.A. dan T.A. Hammed. 2009. "Influence of Work Motivation and Time Management on Employess' Performance in Some Selected Industries in Ibadan, Oyo State Nigeria". European Journal of Economics, Finance and administrative Sciences, Issue 16, hal.7:17

Supriyani Diana dan Mahmud Mohamad. 2012. Pengaruh Motivasi, Komitmen dan Kepuasan Kerja Terhadap Kinerja Karyawan Pada Perusahaan BUMN di Kota Surabaya. Jurnal Ekonomi dan Bisnis Volume 1 Nomor 2. Universitas Brawijaya, Malang.

Thoha, Miftah. 2009. Perilaku Organisasi:

Konsep Dasar dan Aplikasinya.

Rajawali Pers. Jakarta.

Terry, George R. dan Leslie W. Rue. 2010.

Dasar-dasar Manajemen. Bumi Aksara, Jakarta.

Wahyuni, Evi, "Pengaruh Budaya Organisasi dan Gaya Kepemimpinan Terhadap Kinerja Pegawai Bagian Keuangan Organisasi Sektor Publik dengan Motivasi Kerja Sebagai Variabel Intervening", Jurnal nominal /volume IV nomor 1/tahun 2015) Universitas negri Yogyakarta.

Wibowo. 2007. Manajemen Perubahan. Edisi kedua. Rajawali Pers, Jakarta.

Widodo, Tri. 2010. "Pengaruh Lingkungan Kerja, Budaya Organisasi, Kepemimpinan terhadap Kinerja (Studi Pada Pegawai Kecamatan Sidorejo Kota Salatiga)". Jurnal Ilmiah Among Makarti.

http://m.minangkabaunews.com/artikel6759-dinkop-umkm-padang-beri-pelatihanpembuatan-kemasan.html http://nasional.republika.co.id/berita/nasiona 1/umum/14/07/24/n97zl2-undp-ipmindonesia-di-peringkat-108-dari-187-negara 